\title{
Natureza e corpo na segunda fase de Merleau-Ponty
}

\author{
Nature and body in the second phase of Merleau-Ponty
}

do) $10.21680 / 1983-2109.2020 \mathrm{v} 27 n 54 I D 20286$

\author{
Jeovane Camargo \\ Universidade Federal de São Carlos (UFSCAR) \\ 0000-0002-6960-6110 \\ acasadeasterion@gmail.com
}

Resumo: Procuramos mostrar como Merleau-Ponty, nos cursos que formam A Natureza (de 1956 a 1960), compreende a natureza e o corpo humano. Nesse período, o filósofo apresenta uma reformulação de seu pensamento, especialmente em relação à Fenomenologia da percepção (1945). Além disso, tentamos apresentar também como a relação interna entre a natureza e o corpo se realiza por meio da noção de desejo.

Palavras-chave: Merleau-Ponty; Natureza; Corpo; Sensível.

Abstract: We intent to show how Merleau-Ponty, in the courses that form The Nature (from 1956 to 1960), understands nature and the human body. At this moment, the philosopher presents a reformulation of his thought, especially regarding the Phenomenology of perception (1945). In addition, we try to present also how the internal relationship between nature and body achieve itself through the notion of desire.

Keywords: Merleau-Ponty; Nature; Body; Sensitive.

\section{INTRODUÇÃO}

O objetivo do presente artigo é apresentar as concepções da segunda fase do pensamento de Merleau-Ponty, contidas nos cursos que ele ministrou no Collège de France, entre 1956 e 1960, e que formam o texto de A Natureza. Nesses cursos, Merleau-Ponty realiza um reajuste em seu pensamento, corrigindo algumas das teses das suas obras iniciais, como $A$ estrutura do comportamento (1942) e Fenomenologia da percepção (1945). Uma das teses iniciais que é abandonada, é a ideia de que a natureza é sem produtividade, sendo reservado ao corpo o papel de portador de sentido. Desde que era o corpo que trazia as equivalências sensoriais para dentro de uma natureza indiferenciada ("em geral"), reaparecia ali o dualismo que o pensador tentava, no entanto, ultrapassar. Para superar esse problemático dualismo inicial, Merleau-Ponty aproxima-se de algumas pesqui- 
sas científicas, como as investigações de Whitehead, Coghill e Gesell e também Uexküll, as quais lhe ajudam a encontrar uma noção de natureza que supere o dualismo ainda presente em sua primeira fase. Por isso, nos anos em que ele ministrou os cursos de $A$ Natureza, aparece uma natureza que é produtiva por si mesma. Além disso, essa natureza deve portar nela mesma a temporalidade, outro problema das obras iniciais, posto que nestas a temporalidade era uma virtude exclusiva de um dos polos da correlação, justamente o corpo.

Procuramos mostrar ainda como essa natureza, que é passagem e temporalidade por si mesma, articula-se com o desejo, noção pouco explorada nas obras iniciais, mas que, entretanto, já estava lá presente. Para trazer todos esses elementos à tona, passaremos em revista as concepções mais decisivas de $\mathrm{A} \mathrm{Na}$ tureza, como as ideias de natureza como passagem, como atividade pelo prazer, além da necessária articulação destas ideias com o corpo, o qual se mostra então como corpo libidinal.

\section{A NATUREZA COMO PASSAGEM}

Nos cursos de A Natureza (1956-1960), Merleau-Ponty empreende um alargamento da concepção sobre a Natureza em parte já apresentada no período intermediário da sua obra. A Natureza que surge desses cursos não mais supõe um espectador, o qual traria as equivalências sensoriais e o escoar temporal para o seio do mundo, como acontecia na Fenomenologia da percepção. A Natureza dos cursos no Collège de France é sensibilidade e passagem antes da correlação com o corpo. O que marca o abandono da concepção fenomenológica do ser-para-nós e a investigação do ser anterior à correlação.

No primeiro curso, dedicado à história do conceito de Natureza, MerleauPonty mostra que alguns filósofos aproximam-se de uma concepção da Natureza como pré-objetiva, contudo não desenvolveram tal ideia. Descartes concebe, primeiramente, a Natureza a partir da prioridade do infinito, a partir da ideia de Deus. A Natureza é a "realização exterior de uma racionalidade que está em Deus" (MERLEAU-PONTY, 2006a, p. 12). Ela é um em si, positividade absoluta, sem orientação e sem interior. Já ao tratar do problema da união da alma e do corpo, Descartes parece operar certa ruptura em relação à sua concepção anterior de Natureza. O mundo tal como conhecido pelos sentidos resiste então ao entendimento puro. Na percepção natural, a convergência dos olhos, por exemplo, parece realizar um "julgamento natural" (MERLEAU-PONTY, 2006a, p. 27). Isso 
revela uma especificidade do corpo, ele parece possuir atributos que, a princípio, eram reservados somente à alma. Em consequência, a extensão pode ser algo mais que pura exterioridade ou objeto partes extra partes. No entanto, Descartes ainda subsume o corpo à alma, de modo que a especificidade do corpo mostra-se como um irracionalismo da vida.

Kant, por um lado, é mais humanista que Descartes ao fazer o ser repousar no homem. Por outro lado, ele mostra que a intuição sensível revela certa "facticidade da experiência" (MERLEAU-PONTY, 2006a, p. 32), a referência a algo que não é conhecido de antemão, sobre o qual a atividade subjetiva opera. Haveria portanto um termo de referência, a relação com um objeto. A atividade subjetiva, porém, como capacidade de ordenação, de dar leis, torna o termo de referência coextensivo à subjetividade, transformando assim a referência externa em construção subjetiva ${ }^{1}$.

Husserl, por seu lado, concebe primeiramente, nas Ideen II, a esfera das puras coisas, "coisas puramente materiais, como mesas, das quais vemos apenas a camada de materialidade, ou homens, dos quais só vemos a camada de animalidade" (MERLEAU-PONTY, 2006a, p. 119). A Natureza de Husserl, nesse período, é tal qual a cartesiana, um em si correlativo do conhecimento puro. Mais tarde, Husserl encontra uma camada mais originária, ele descobre o mundo percebido, em relação ao qual as blosse Sachen são idealizações, construções ulteriores. Essa camada originária é formada pela relação do corpo com as coisas. Apesar dessa descoberta, contudo, Husserl permanece um idealista transcendental. Ele localiza o percebido no plano da doxa, como análise preparatória a ser ultrapassada em direção à Urdoxa, a esfera da constituição transcendental.

$\mathrm{Na}$ segunda parte do curso sobre as concepções históricas da Natureza, Merleau-Ponty passa em revista algumas concepções científicas. Como exemplar da física clássica, Laplace concebe o mundo como pura positividade, inteiramente extensão. Decompondo-se o complexo em simples, pode-se inferir uma série de causalidades, mas estas só existem para os homens, já que passado e futuro não existem no mundo tomado em si mesmo, o qual é uma plenitude. Dessa forma, a concepção determinista de Laplace reproduz a ontologia cartesiana (Cf. MERLEAU-PONTY, 2006a, p. 142-143).

$\mathrm{Na}$ física contemporânea, por sua vez, constata-se que há diferentes interpretações na compreensão da articulação entre ondas e corpúsculos, o que se

\footnotetext{
1 "A ideia cartesiana de Natureza não tinha sido completamente exorcizada por Kant. Certamente, com Kant a Natureza já não é construída por Deus, mas pela Razão humana. Entretanto, o conteúdo permanece idêntico” (MERLEAU-PONTY, 2006a, p. 57).
} 
deve ao modo como cada pesquisador interfere no experimento. Em face disso, encontra-se uma probabilidade no tecido do real (Cf. MERLEAU-PONTY, 2006a, p. 146). Isso quer dizer que as diferentes concepções físicas não se desenvolvem no interior de um sistema espaço-temporal definido, como acontece na física clássica. Enquanto, para esta, o aparelho é um prolongamento dos sentidos, uma sensorialidade mais precisa que torna possível conhecer o estado de uma coisa, na mecânica quântica o aparelho não amplifica os poderes dos sentidos, ele não apresenta o objeto. O aparelho realiza antes uma antecipação ou fixação do fenômeno ou do objeto. Ele oferece uma probabilidade. Assim, o que se conhece não é uma Natureza definida, senão que artificial (Cf. MERLEAU-PONTY, 2006a, p. 150). Não se tratando de um objeto em si, como na ontologia cartesiana, o que se constata é que o "objeto quântico é um objeto que não tem existência atual" (MERLEAU-PONTY, 2006a, p. 152). Há, portanto, uma nova relação entre a coisa observada e a medida: a relação de probabilidade. Essa nova relação revelada pela física moderna aproxima-se, assegura Merleau-Ponty, do problema da percepção: "No campo natural, vou encontrar seres ambíguos, que não são nem ondas nem corpúsculos" (MERLEAU-PONTY, 2006a, p. 160). Nesse sentido, as coisas percebidas revelam-se "seres prováveis", "um feixe de probabilidades", "seres negativos, dos quais toda a essência consiste em ser uma ausência" (MERLEAU-PONTY, 2006a, p. 160). As pesquisas da física levam a se tomar consciência do percebido, o qual se revela como um dado não imediato. O espaço perceptivo mostra-se como um espaço polimorfo. Contudo, o percebido não é uma construção artificial em relação à Natureza, mas o que ensina à física uma unidade, uma realidade que reúne uma série infinita de grandezas, um primeiro modelo do Ser (Cf. MERLEAU-PONTY, 2006a, p. 161, 169, 170). A partir dessa unidade original, a ciência procura fornecer uma unidade articulada do Ser. É a partir dessa primeira unidade, dessa percepção do espaço, que a física se torna possível. Enquanto espaço polimorfo e de probabilidade, a percepção se junta à física quântica, mostrando que o espaço euclidiano não é o único espaço real, senão que uma métrica entre outras possíveis (Cf. MERLEAU-PONTY, 2006a, p. 166).

Tendo em vista a pesquisa da física contemporânea e, em especial, a pesquisa de Whitehead, Merleau-Ponty descobre uma Natureza que é uma atividade de passagem, um tempo cósmico que assegura uma interioridade, a concatenação dos acontecimentos uns com os outros. Essa passagem da Natureza não deve ser pensada, porém, a partir do flash, do presente instantâneo, como fazem a ciência clássica, como por exemplo, Laplace, e a tradição filosófica, de Santo 
Agostinho a Bergson e Sartre. Segundo Whitehead, o pensamento clássico pensa o tempo, e, por conseguinte, a Natureza, tendo como fundamento um ponto flash, em relação ao qual o passado não é mais e o futuro ainda não é. A Natureza é pensada como uma infinidade de pontos temporais e espaciais, e o mundo como um sistema de leis eternas. Corroborando esse raciocínio, a filosofia concebe a matéria como um presente instantâneo e a memória e o passado como atividades subjetivas. Ela adiciona ao Em si o Para si. Essa crítica vale também para a Fenomenologia da percepção, na qual o mundo ele mesmo, isto é, sem espectador, é sem passagem temporal. O tempo só aparece no mundo quando um corpo nasce, trazendo assim o alhures, o outrora e o amanhã. Por meio desse procedimento, os acontecimentos definem-se pelo instante presente e o passado apresenta-se como memória subjetiva; o tempo torna-se uma característica própria da subjetividade. De outro lado, Whitehead apresenta a Natureza como uma passagem, uma "concrescência" ou um "desdobramento espaço-temporal" (MERLEAU-PONTY, 2006a, p. 196, 194); ela se realiza por meio da concatenação dos eventos, como uma interioridade dos acontecimentos, segundo sua inerência mútua (Cf. MERLEAU-PONTY, 2006a, p. 190, 191). "Mas há um tempo inerente à Natureza. Esse tempo, em Whitehead, é inerente às coisas, ele nos envolve, na medida em que participamos das coisas, em que participamos da passagem da Natureza" (MERLEAU-PONTY, 2006a, p. 194). Isso quer dizer que a unidade do mundo, assim como a memória, não é produto da subjetividade. A passagem da Natureza é a infraestrutura que faz a unidade do corpo e dos diferentes observadores, de modo que ela é uma Natureza para vários. Ela faz com que a tomada de consciência própria do corpo humano apareça como "participação" na passagem do tempo natural. A passagem da Natureza é a "potência criadora da existência" (MERLEAU-PONTY, 2006a, p. 198), uma pulsação² ou um impulso ${ }^{3}$ (Cf. MERLEAU-PONTY, 2006a, p. 192, 195) que, enquanto sucessão ${ }^{4}$, passagem, supera retomando, concatenando. Nesse sentido, por um lado, ela é tanto generalidade como individualidade e, por outro, ela é a memória do mundo (Cf. MERLEAU-PONTY, 2006a, p. 192, 197).

A Natureza se dá na "revelação sensível" (Cf. MERLEAU-PONTY, 2006a, p. 192), o que quer dizer que o que é percebido é tanto para o observador como nas coisas. No entanto, ela não se esgota em suas manifestações, guardando sempre uma opacidade. O corpo, dessa forma, é um modo ${ }^{5}$ da passagem da Natureza: "o

\footnotetext{
${ }^{2}$ Pulsation (MERLEAU-PONTY, 1994, p. 162).

${ }^{3}$ Poussée (MERLEAU-PONTY, 1994, p. 159).

4 "Pertence à essência do universo passar a um futuro" (MERLEAU-PONTY, 2006a, p. 199).

5 “O homem é modo, tanto quanto as células animais” (MERLEAU-PONTY, 2006a, p. 199).
} 
tempo realiza a 'fruição de si mesmo' no organismo" (MERLEAU-PONTY, 2006a, p. 196). Isso significa que o corpo prolonga a passagem da Natureza, que as "partes da Natureza admitem entre elas relações do mesmo tipo que as de meu corpo com a Natureza" (MERLEAU-PONTY, 2006a, p. 192). Visibilidade e tangibilidade, por exemplo, são propriedades compartilhadas tanto pela Natureza como pelo corpo. A passagem da Natureza só está inscrita no corpo porque o corpo está inscrito na Natureza (Cf. MERLEAU-PONTY, 2006a, p. 195, 196). "A Natureza caminha, por uma série de desequilíbrios, para a realização do homem que se torna seu termo dialético" (MERLEAU-PONTY, 2006a, p. 70).

\section{A NATUREZA COMO ATIVIDADE PELO PRAZER}

No segundo curso, Merleau-Ponty se serve das pesquisas de Coghill e Gesell para tratar da animalidade. Estes procuram negar a teoria anatômica do desenvolvimento, a qual liga cada fase do desenvolvimento animal a uma fase do amadurecimento neural, de modo que a montagem do animal se faria peça por peça. Alguns experimentos mostram, ao contrário, que já há esboços de fibras e outros representantes locais antes mesmo que as partes sejam independentes. Isso quer dizer que as reações locais estão integradas a um comportamento. Há esboços do organismo final no amadurecimento de um embrião. Tais esboços são ainda estranhos à situação presente, porém necessários ao desenvolvimento futuro. O que Coghill descobriu é que existem polaridades ou gradientes: nas diferentes regiões do corpo apresentam-se níveis de suscetibilidade a diferentes impulsos (Cf. MERLEAU-PONTY, 2006a, p. 232). Através desses gradientes, os embriões assumem diferentes formas em seu amadurecimento, como redondo ou alongado, ou diferentes polos, como vegetativo ou animal. Há, portanto, um sistema pré-neural de integração, uma "potencialidade intrínseca de crescimento", um sistema dinâmico (Cf. MERLEAU-PONTY, 2006a, p. 234) que não se desenvolve peça por peça, mas por esboços. Em um feto de oito semanas, por exemplo, o polegar se afasta dos outros dedos, o que antecipa o movimento de preensão que só será realizado pela criança um ano após seu nascimento. Isso quer dizer que um desenvolvimento local antecipa a manifestação de um comportamento. De modo semelhante, os principais aspectos do eletrocardiograma humano de um feto de noves semanas e meia de vida apresentam-se da mesma maneira que na fase adulta - isso significa que determinados comportamentos se antecipam aos dispositivos neurais que os coordenariam, já que neste feto não há ainda controle nervoso do coração. O desenvolvimento do organismo é assim 
um comportamento que antecipa seu desenvolvimento futuro. Em cada fase do desenvolvimento do organismo realiza-se, diz Merleau-Ponty, "certo poder", "uma possibilidade interior ao organismo em crescimento" (MERLEAU-PONTY, 2006a, p. 235). O organismo ou o embrião desenvolve-se em referência ao futuro. Os níveis superiores integram, reincorporam os níveis inferiores, e estes se desenvolvem em referência a uma totalidade ausente. Nesse sentido, o organismo é "Gestalt do organismo articulado" (MERLEAU-PONTY, 2006a, p. 236). A totalidade não está dada, ela emerge (Cf. MERLEAU-PONTY, 2006a, p. 237) de cada fase, e, contudo, o organismo parece progredir em sua direção. Não se trata, assegura Merleau-Ponty, de colocar um princípio regulador por trás do organismo, porém não se pode deixar de encontrar ali um princípio regulador. O amadurecimento se realiza em referência a um vazio, falta ou ausência que mais tarde será preenchido. O organismo se desenvolve segundo um princípio negativo, um desvio em relação à fase atual. O embrião amadurece através de um desenvolvimento em espiral, ou através de reações oblíquas (Cf. MERLEAU-PONTY, $2006 a$, p. 238, 242). Cada novo esboço cria um desequilíbrio na fase atual, estabelecendo as condições da fase seguinte. Dessa forma, o corpo pode ser definido como um "sistema de potências motoras que se entrecruzam para produzir um comportamento" (MERLEAU-PONTY, 2006a, p. 242). Em outra passagem, retomando Whitehead, Merleau-Ponty define vida como "a realidade de uma passagem" (MERLEAU-PONTY, 2006a, p. 256). A passagem acontece, segundo a morfologia dinâmica do organismo, como reincorporação de condutas inferiores em um nível superior, ou um desenvolvimento em espiral (Cf. MERLEAU-PONTY, 2006a, p. 242). O avanço (moving on) da Natureza, seu "movimento para diante" (MERLEAU-PONTY, 2006a, p. 243), acontece como um progresso no qual as fases inferiores permanecem nas fases superiores, em que as primeiras são integradas nas seguintes, em um processo de sucessão que é ao mesmo tempo superação e retomada. Há assim uma indivisão entre o crescimento do organismo e a ausência ou totalidade que rege seu desenvolvimento. Cada fase é a instauração de um campo ou de uma dimensão, a qual dá sentido à situação em que o organismo se encontra. Tal dimensão, princípio negativo, ausência, forma ou totalidade é, afirma Merleau-Ponty, "o atributo fundamental do ser vivo" (Cf. MERLEAU-PONTY, 2006a, p. 245, 255). Dessa forma, "aprender a vida nas coisas é aprender, nas coisas como tais, uma falta" (MERLEAU-PONTY, 2006a, p. 257).

A Fenomenologia da percepção (1945) também concebia a manifestação das coisas segundo uma presença e uma ausência concomitantes. O termo não-ser

\footnotetext{
${ }^{6}$ un certain pouvoir (MERLEAU-PONTY, 1994, p. 193).
} 
não significa uma interioridade - como querem Moura e os primeiros textos de Barbaras - , mas ele é forjado para explicitar um aspecto da estrutura perceptiva. Por um lado, ele diz respeito ao corpo como o fundo diante do qual os objetos aparecem: nesse sentido, a percepção é uma falha, uma fissura, um vazio, uma "dimensão de ausência" em relação à qual o objeto se oferece. Por outro, ele refere-se às várias possibilidades perceptivas que se anunciam em uma tomada, mas que não são atuais como o objeto visto (figura); nesse sentido, não-ser é um excesso, pois toda perspectiva se faz em um fundo de perspectivas possíveis. Essa virtualidade passível de tornar-se atual se dá como falta, como ausência. Segundo a Fenomenologia da percepção, mesmo o empirismo, apesar de seus limites, concede que "toda coisa se oferece sobre um fundo que não é uma coisa, o presente entre dois horizontes de ausência, passado e futuro" (MERLEAU-PONTY, 2006b, p. 48; grifo meu). Essa estrutura, Merleau-Ponty a nomeia como mundo, ou "horizonte latente", em que a "presença e a ausência dos objetos exteriores são apenas variações no interior de um campo de presença primordial, de um domínio perceptivo sobre os quais meu corpo tem potência" (MERLEAU-PONTY, 2006b, p. 136; grifo meu). Outra passagem reforça esta interpretação:

fixado neste campo transcendental que se abriu desde a minha primeira percepção [no nascimento do corpo no mundo] e no qual toda ausência é apenas o avesso de uma presença [...] sinto-me dedicado a um fluxo de vida inesgotável do qual não posso pensar nem o começo nem o fim, já que sou ainda eu enquanto vivo quem os pensa, e já que assim minha vida sempre precede-se e sobrepõe-se a si mesma. (MERLEAU-PONTY, 2006b, p. 488; grifo meu)

Aberto ao mundo por meio de uma perspectiva, o sujeito sente "a angústia de ser ultrapassado" pela totalidade da vida, a qual engloba também a morte e outrem (MERLEAU-PONTY, 2006b, p. 489; grifo meu). Uma vida inesgotável, que não pode ser abarcada em uma visada, que sempre se dá por meio de uma ausência, seja a do corpo seja a dos horizontes latentes, e, em relação à qual, o sujeito sente a angústia, a insatisfação de ser sempre ultrapassado e nunca a possuir por completo. E se "o próprio do desejo é que o desejado não o preenche senão o atiçando" (BARBARAS, 1999, p. 137), isso também não deixa de encontrar suas ressonâncias na estrutura temporal, na qual o adquirido nunca fecha a intencionalidade, mas já aparece como algo a ser ultrapassado, como apoio para se chegar a uma nova significação. Exatamente como a percepção merleaupontiana atualiza uma tomada sobre um fundo de perspectivas possíveis, o mundo de Barbaras "corresponde a essa totalidade intotalizável, a esse invisível que toda percepção ao mesmo tempo atualiza e carece (manque)" (BARBARAS, 1999, p. 154; grifo meu). Assim, é preciso reconhecer, com Merleau-Ponty, "que o pudor, o desejo, o amor em geral tem uma significação metafísica”, pois as "con- 
tradições do amor ligam-se [...] a um drama mais geral que se refere à estrutura metafísica de meu corpo [...]" (MERLEAU-PONTY, 2006b, pp. 230 e 231). O desejo possui, pois, uma significação metafísica, ele diz respeito ao âmago mesmo da temporalidade ou da intencionalidade.

Também $A$ instituição - A passividade (1954-55) destaca o desejo como "vontade do impossível", "impossibilidade imanente" (MERLEAU-PONTY, 2003, p. 56). Na puberdade e na fase madura, dá-se um desejo do impossível, pois a criança não pode concretizar seu impulso de tomar o lugar do pai nem os amantes encontram satisfação no coito, eles não podem atingir o outro nele mesmo. Os prazeres particulares apenas incitam a novas buscas, nunca encontram sua satisfação última. Há sempre uma falta, uma ausência perpassando cada prazer (tomada) particular.

A passagem da Natureza, a morfologia dinâmica do organismo funciona também segundo o modelo diacrítico da linguagem. Neste, cada palavra só difere de sentido em relação a outras palavras, segundo seu lugar na frase, segundo o momento histórico e o estado da língua (Cf. MERLEAU-PONTY, 2006a, p. 238, 240). Do mesmo modo, o encadeamento temporal não se faz por meio da articulação de pontos instantâneos (identidades), mas segundo fases ou seres não uniformes, que só existem na passagem de cada um deles (Cf. MERLEAU-PONTY, 2006a, p. 197), que só existem em sua relação ou em seu encadeamento.

Em seguida, apoiando-se na pesquisa de Uexküll, Merleau-Ponty observa que o desenvolvimento do organismo se faz segundo sua articulação com o meio, em uma relação de conjunto em que cada elemento está em relação de sentido. Uexküll nomeia essa articulação de Umwelt, a relação entre animal e meio na qual o mundo está implicado pelos movimentos do animal e ao mesmo tempo regula seus movimentos (Cf. MERLEAU-PONTY, 2006a, p. 284). A Umwelt é o meio "ao qual o animal se dirige, que existe para o comportamento de um animal", "é o meio ambiente de comportamento" (MERLEAU-PONTY, 2006a, p. 271). A Umwelt é a indivisão animal-meio, a "contaminação de um dos dois termos pelo outro" (MERLEAU-PONTY, 2006a, p. 302). Não se trata de colocar relações causais entre o animal e o meio, mas de dizer que cada estímulo exterior foi ao mesmo tempo provocado ou condicionado pelo movimento do animal. Mesmo os chamados animais máquina - animais aos quais o meio exterior não parece regular - não são determinados por relações causais nem se desenvolvem no sentido de atingir uma meta preestabelecida. Os animais são capazes de plasticidade, eles possuem um comportamento ou conduta que deposita no mundo físico um "acréscimo de significação" (MERLEAU-PONTY, 2006a, p. 280), crian- 
do uma Umwelt. A vida assim é "a abertura de um campo de ações" (MERLEAUPONTY, 2006a, p. 281), o que significa, em consequência, que as mesmas condições exteriores podem gerar diferentes comportamentos. Embora não se dirija a uma meta pré-determinada, o animal é, porém, obcecado por uma totalidade que transcende a particularidade de cada meio (Cf. MERLEAU-PONTY, 2006a, p. 287, 297). Ao tentar esclarecer o que seria essa atividade obcecada pela totalidade, Merleau-Ponty primeiro a entende no sentido de Uexküll, como certa Natureza, ou Subjektnatur, a qual, no limite, seria incognoscível. Isso leva a se afirmar, em seguida, uma "magia natural", uma "ação mágica”, um "milagre", um "princípio obscuro", o "misterioso da vida" (MERLEAU-PONTY, 2006a, p. 196, 301, 302, 305). Entretanto, se não se quiser acusar Merleau-Ponty de cair em certo "irracionalismo" por sustentar um processo criador que resiste a todo comentário, isto é, por admitir o mistério como critério explicativo último, então é preciso lembrar que ele reconhece essa magia da vida como a passagem da Natureza "inobservável de perto, mas que seguramente se faz" (MERLEAU-PONTY, 2006a, p. 256). Essa passagem realiza-se em referência a uma ausência, o que significa que as atividades acontecem como "atos no vazio" ou "atividade no vazio" (MERLEAU-PONTY, 2006a, p. 317), sem uma meta ou um objeto definido. Graças a esse caráter lacunar desenha-se uma atividade simbólica, em que as ações são executadas como "faz de conta", como "substitutas" das ações efetivas (Cf. MERLEAU-PONTY, 2006a, p. 317) - o estorninho simula caçar moscas -, quando a ação visa o irreal ou o inatual, quando o instinto tem por objeto uma imagem, quando se instaura uma distância entre o fazer e o ver (Cf. MERLEAU-PONTY, 2006a, p. 311, 312, 314, 320). Se o organismo amadurece sem uma meta, se o instinto é sem objeto, é porque a tendência instintiva e o funcionamento do organismo são uma "tensão que quer encontrar um relaxamento" (MERLEAUPONTY, 2006a, p. 314), que quer uma satisfação. Um objeto particular é apenas um meio de resolver a tensão (ou "drama vital"), a qual continua, pois o objeto atual não é seu fim último. Cada tomada ou organização é um esboço que será superado pelo esboço seguinte. $\mathrm{O}$ animal, assim, quer e não quer o objeto, já que ele visa mais o irreal do que o real (Cf. MERLEAU-PONTY, 2006a, p. 314). A atividade no vazio, ao realizar-se em referência a um futuro, a uma ausência, insere na Natureza algo não previsto - visar o inatual, fazer de conta - , conferindo assim um caráter de liberdade à ação, realizando um simbolismo, uma précultura ou uma "cultura animal" (Cf. MERLEAU-PONTY, 2006a, p. 286, 315, 322).

Se a indivisão entre animal e meio circundante, que se expressa tanto no fenômeno da Umwelt como no do mimetismo - semelhança e imitação dos 
animais entre si e com o meio -, não deve ser entendida como magia, parece ser porque, retomando-se Schopenhauer, as "divisões do 'mundo da representação" escondem a "unidade do "mundo da vontade" (MERLEAU-PONTY, 2006a, p. 301). Isto é, porque os fenômenos da animalidade - tensão ou drama que busca uma satisfação - mostram-na como "uma atividade pelo prazer" (MERLEAUPONTY, 2006a, p. 312, 313).

A Umwelt, o mimetismo e a Prägung são um diálogo (Cf. MERLEAUPONTY, 2006a, p. 322) entre animal e meio, mas tal que nele não se prioriza um dos polos da relação. A relação é antes de imbricação, expressão recíproca, indivisão, situação de conjunto, interanimalidade (Cf. MERLEAU-PONTY, 2006a, p. 308,321 ). Acontece uma relação especular dos animais entre si e com o meio. Esta é também uma relação perceptiva; contudo, ela acontece aquém da percepção ou do saber humano7. Se "o Ser não pode ser definido fora do ser percebido" (MERLEAU-PONTY, 2006a, p. 307), é porque o caráter perceptivo em questão não é o humano, mas uma percepção animal, ou a sensibilidade do mundo: "O que o mimetismo parece [...] estabelecer é que o comportamento só se pode definir por uma relação perceptiva" (MERLEAU-PONTY, 2006a, p. 307). Segundo Merleau-Ponty, as relações entre os aspectos exteriores de uma espécie animal são tantas quanto as relações internas entre as partes do corpo de cada animal. Há uma relação entre "o aspecto exterior do animal e sua capacidade de visão". Isso quer dizer que "o animal vê conforme ele é visível" (MERLEAU-PONTY, 2006a, p. 307). Nesse sentido, existe uma "relação perceptiva antes da percepção propriamente dita" (MERLEAU-PONTY, 2006a, p. 307). Segundo Merleau-Ponty, em um órgão do sentido, "a matéria está disposta de tal modo que é sensível a um meio no qual o órgão não está" (MERLEAU-PONTY, 2006a, p. 302). A matéria é um tipo de sensibilidade iminente, o que torna possível que a estrutura fisiológica de um aparelho atinja as formas do meio circundante. A estrutura do órgão do sentido, sua capacidade de atingir as coisas, é semelhante à articulação entre a borboleta e o meio, como se uma estrutura já levasse em conta a outra. Tal relação perceptiva entre o ser vivo e o meio se mostra já antes de cada ato perceptivo, o que vale tanto para os animais como para os homens. A relação especular dos animais entre si e com seu meio é uma relação perceptiva, ela é o que define a interanimalidade. Essa relação diacrítica entre ser vivo e meio, ou essa passagem da Natureza se dá sem o testemunho humano, ela se dá "quer o saibamos ou não"

\footnotetext{
${ }^{7}$ Merleau-Ponty admite, junto com Uexküll, que a Umwelt humana engloba a dos animais. Entretanto, nenhuma Umwelt é total, já que cada uma se organiza em vista de uma totalidade ausente. Assim, a Umwelt humana é ultrapassada por uma Umgebung, a qual se revela como a Natureza, a realidade absoluta que transcende cada meio particular (Cf. MERLEAU-PONTY, 2006a, p. 287).
} 
(MERLEAU-PONTY, 2006a, p. 197). Tal sensibilidade exclui o ponto de vista privilegiado da percepção humana. O que se manifesta não supõe uma possível percepção humana; assim, a correlação e a identidade ser-aparecer são recusadas.

A sensibilidade da Natureza não supõe o ponto de vista humano e ela se faz segundo horizontes de ausência, segundo um princípio de negatividade. O organismo se desenvolve em referência a um futuro, obcecado por uma totalidade sempre ausente, o que quer dizer que cada manifestação ou fase comporta possibilidades que não são percebidas atualmente. Desde que tal referência ao ausente é a própria passagem da Natureza, então mesmo na fase adulta do organismo há uma dimensão invisível ou latências que não se manifestam. A negatividade ela mesma não se manifesta, estando sempre além de cada tomada particular. Apesar de criticar certo humanismo heideggeriano, Merleau-Ponty elogia também seu não-humanismo, segundo o qual há uma "relação com o Ser que não pode fazer parte do equipamento humano" (MERLEAU-PONTY, 2006a, p. 223). A dimensão sensível é tal que ela é uma sensibilidade própria, extrapolando o aparato perceptivo humano. Embora a perspectiva humana surja na Natureza, esta não supõe um espectador que testemunhe seu desdobrar temporal. A Natureza é passagem por si mesma, ela é "pura passagem" (MERLEAU-PONTY, 2006a, p. 197). Essa concepção é uma radical transformação em relação à Fenomenologia da percepção, na qual as equivalências corporais (espectador) trazem para o seio do mundo - o qual, considerado em sim mesmo, é uma exterioridade pura - o escoamento temporal. Nos cursos de $A$ Natureza, "as formas do meio circundante" possuem estruturas que não necessitam de um testemunho para se realizarem.

A ontologia que Merleau-Ponty procura expor diz respeito a um Ser cujas articulações de seres são recortes ou modalizações do Ser total (Cf. MERLEAUPONTY, 2006a, p. 332). O que ele procura é o nexus ou o vinculum entre homem e Natureza. Nesse sentido, diz Merleau-Ponty, é necessário que haja uma relação entre homem e Natureza e mesmo que "a Natureza fora de nós nos seja desvelada pela Natureza que nós somos" (MERLEAU-PONTY, 2006a, p. 332). Como uma das articulações ou modos do Ser aparece o corpo humano. Por isso, a Natureza exterior pode ser conhecida por meio da natureza humana, posto que ambas comungam de um mesmo material (Cf. MERLEAU-PONTY, 2006a, p. 351) - determinadas propriedades sensíveis, como visibilidade e tangibilidade, são comuns a ambas - , e não porque a Natureza seja dada pela percepção humana, pelo testemunho humano. Em outro momento, Merleau-Ponty assegura que o Ineinander de fato (a Natureza) é ratificado pelo Ineinander vivido, percebido (a 
natureza do corpo humano). A sensibilidade humana pode confirmar a sensibilidade da Natureza porque a humanidade é "outra maneira de ser corpo", isto é, porque o corpo humano é uma modalização do Ser total (Cf. MERLEAU-PONTY, 2006a, p. 336). A Natureza, passando, individua-se, ou seja, dá-se corpos, diferencia-se. Um desses modos ou corpos é o homem.

A ciência clássica e a filosofia de Santo Agostinho a Sartre transformavam a Natureza em pura exterioridade. Ela era apenas o parceiro da consciência nas investidas do conhecimento (MERLEAU-PONTY, 1994, p. 356, Anexo). De forma análoga, ao reservar às equivalências corporais o desdobramento do tempo, a Fenomenologia da percepção fazia da Natureza mero "produto" do conhecimento (MERLEAU-PONTY, 2006a, p. 59). A Terra e os acontecimentos anteriores ao homem pertenciam então ao mundo cultural, eram derivações do percebido. Em A Natureza, apresenta-se uma radical mudança teórica. Segundo MerleauPonty,

Se nós não nos resignamos a dizer que um mundo, do qual as consciências estariam retiradas, é nada, que uma Natureza sem testemunho não teria sido e não seria, é preciso que reconheçamos de alguma maneira o ser primordial que não é ainda o ser sujeito nem o ser objeto. (MERLEAU-PONTY, 1994, p. 357, Anexo)

O Ser anterior ao homem e que lhe serve de solo, de arca da verdade e da cultura ${ }^{8}$ (Cf. MERLEAU-PONTY, 1994, p. 367), é uma produtividade por si mesmo, uma "produtividade originária" (MERLEAU-PONTY, 2006a, p. 204) que "tem sempre necessidade de produzir outra coisa", uma transcendência "sempre recomeçada" (MERLEAU-PONTY, 2006a, p. 60). A Natureza é, como em Schelling, o "princípio bárbaro", o "pré-ser" anterior à reflexão sobre o Ser (Cf. MERLEAUPONTY, 2006a, p. 60, 61). Ao invés de derivar a Natureza de um infinito (Deus) ou da consciência, descobre-se uma "dignidade do finito positivo" (MERLEAUPONTY, 2006a, p. 59), um Ser ao mesmo tempo passivo e ativo, produto e produtividade, uma tomada parcial e um fundo de transcendência ${ }^{9}$ (Cf. MERLEAUPONTY, 2006a, p. 59-60).

A indivisão animal-meio é ao mesmo tempo liberdade dos seres vivos e condicionamento do meio (MERLEAU-PONTY, 2006a, p. 302). Contudo, como se pergunta Merleau-Ponty, qual é o estatuto ou natureza dessa liberdade ou ativi-

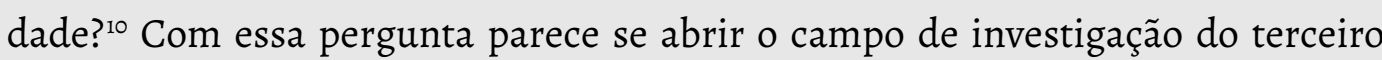

\footnotetext{
8 "Da mesma forma que a arca de Noé continha tudo que podia restar de vivente e de possível, também a Terra pode ser considerada como portadora de todo o possível” (MERLEAU-PONTY, 2006a, p. 127).

9 "Se a Natureza produtora se retirasse do produto, isso seria a morte" (MERLEAU-PONTY, 2006a, p. 60).

10 "A unidade do organismo não repousa no sistema nervoso central, é necessário fazê-la repousar numa atividade” (MERLEAU-PONTY, 2006a, p. 276). “Mas qual é a natureza dessa atividade que projeta uma Umwelt
} 
curso de $A$ Natureza, o qual procura esclarecer a especificidade do corpo humano e, por meio desta, complementar o estatuto do que seja a Natureza.

\section{A NATUREZA E O CORPO LIBIDINAL}

No terceiro curso sobre a Natureza, Merleau-Ponty apresenta a especificidade do corpo humano. A análise do corpo humano, afirma Merleau-Ponty, deve esclarecer as análises precedentes sobre a Natureza e ao mesmo tempo ser esclarecida por elas (Cf. MERLEAU-PONTY, 2006a, p. 347-348). A Natureza explicitada pelos dois cursos anteriores deve ser "esclarecida pela descrição do corpo humano enquanto percipiente: é o mesmo Ineinander que abordamos alternadamente pelas duas pontas" (MERLEAU-PONTY, 2006a, p. 336).

A passagem à consciência humana teria se realizado por meio de uma mudança "morfologicamente ínfima" (MERLEAU-PONTY, 2006a, p. 431): a modalidade bípede possibilitou que as mãos liberassem os maxilares da função de preensão; em consequência, o crânio pode se desenvolver, pois os músculos do maxilar, que aprisionavam o crânio, relaxaram; assim, o cérebro aumentou, o rosto diminuiu e os olhos se aproximaram a ponto de poderem fixar o que as mãos agarravam (Cf. MERLEAU-PONTY, 2006a, p. 425). Essa estrutura seria, indica Merleau-Ponty, a própria exteriorização da reflexão. Se os cientistas não conseguiram encontrar o elo perdido da passagem do humanóide ao homem, é porque, no início, "como todas as formas de transição" (MERLEAU-PONTY, 2006a, p. 424), havia poucos exemplares. Além do mais, não se tratou de uma ruptura, senão que a passagem se deu como uma metamorfose. O homem teria aparecido entre pré-tipos, Sinantropo, pré-humanídeo, de modo que - assim como não se nota a passagem da criança ao adulto posto que a mudança morfológica é ínfima - "de súbito" apareceu o homem ou "o homem entrou sem ruído" (Cf. MERLEAU-PONTY, 2006a, p. 424, 431). A transformação dos órgãos (a metamorfose) se deu a fim de tornar possível a reflexão. Não se trata da transformação do corpo para revestir uma reflexão já total, mas da simultaneidade entre corpo e reflexão. A transformação dos órgãos possibilitou a reflexão senciente e sensível, do corpo que se vê tocando as coisas, que se sente visto por outrem, visível e vidente. A metamorfose dos órgãos possibilitou "a vinda a si do Ser", a reflexividade, o corpo que se vê tocando (Cf. MERLEAU-PONTY, 2006a, p. 432).

no espaço, ou que se antecipa a certos eventos da Natureza? Qual é a natureza dessa atividade?” (MERLEAUPONTY, 2006a, p. 322). 
A relação tocante-tocado é a da atividade-passividade. A relação do corpo consigo mesmo, em que uma mão é ora tocada ora tocante, em que a mão tocante sente que poderia ser tocada pela mão que ela toca, em que os modos passivo e ativo se alternam, é uma única experiência, ou os dois lados de uma única experiência. O corpo enquanto toca é ativo, abertura e, enquanto é tocado, é coisa, passivo. Dessa forma, ele é uma "coisa-abertura para as coisas", o que MerleauPonty também denomina como carne (MERLEAU-PONTY, 2006a, p. 358). Essa estrutura sinestésica permite que o corpo conheça outros corpos e que estes o conheçam, posto que o corpo é visão e coisa vista, vidente e visível. A estrutura estesiológica possibilita que o corpo tenha uma "aplicação a si mesmo", que ele tenha um "interior". Ao mesmo tempo, a estesiologia humana possibilita que o corpo perceba outros corpos como percipientes (Cf. MERLEAU-PONTY, 2006a, p. 352) - através da mesma capacidade que a mão tocante reconhece na mão tocada, a qual pode tornar-se tocante, o corpo reconhece em outro corpo o poder que este tem de perceber, de ser senciente. Como na imagem no espelho, a visão torna possível que o corpo veja algo dele nas coisas (Cf. MERLEAU-PONTY, 2006a, p. 439).

Em relação às coisas, ao mundo, o corpo obtém um afastamento, o qual permite que a Umwelt não seja dissimulada, que se tenha um saber da Umwelt ${ }^{11}$ (Cf. MERLEAU-PONTY, 2006a, p. 349, 350). Entretanto, a relação corpo e mundo não se dá por meio de um corpo que porta as capacidades perceptivas, as equivalências sensoriais, uma subjetividade, e um mundo cuja organização só se realiza quando um corpo nasce, um mundo do qual a temporalidade está ausente, como acontecia na Fenomenologia da percepção. A Natureza de que tratam os cursos no Collège de France possui uma sensibilidade própria, não dependente do corpo humano, ela é um "tecido de ser pré-objetivo", um "ser pré-empírico arquitetônico" (MERLEAU-PONTY, 2006a, p. 433, 335) de onde o corpo emerge. O que há, assegura Merleau-Ponty, é o "ser visível ou sensível" (MERLEAU-PONTY, 2006a p. 429), e este comporta também um invisível, "lados ocultos": o "todo do Ser" é visível e invisível (MERLEAU-PONTY, 2006a, p. 430). O corpo humano é um Ineinander, isto é, a inerência de si no outro e do outro a si. Há também um Ineinander entre corpo humano e animalidade — de modo que a relação homem e animal não é hierárquica, mas lateral, um "estranho parentesco". E há um Ineinander entre corpo e mundo, daquele ao mundo e deste ao corpo. O surgimento do homem na Natureza, sua emergência em um ser pré-objetivo, prévio, quer

\footnotetext{
11 "É no homem que as coisas se tornam por si mesmas conscientes; mas a relação é recíproca: o homem é o vir a ser consciente das coisas. A Natureza caminha, por uma série de desequilíbrios, para a realização do homem que se torna seu termo dialético". (MERLEAU-PONTY, 2006a, p. 70)
} 
dizer que a relação senciente sensível aparece como característica fundamental do corpo humano porque ela já era uma possibilidade da própria Natureza. Trata-se de um "Logos do mundo natural", um "Ineinander de fato" que se duplica em corpo, linguagem, cultura ${ }^{12}$ (Cf. MERLEAU-PONTY, 2006a, p. 343, 336). O "interior" do corpo, esse lado oculto, invisível, é o avesso, o outro lado do visível, um afastamento em relação ao visível (Cf. MERLEAU-PONTY, 2006a, p. 336, 337). Segundo Merleau-Ponty, ao contrário do tátil, no qual a relação é imediata e não há a possibilidade de espelhamento, a visão traz certo distanciamento, ela quebra o imediato: como na imagem no espelho, ela permite a contemplação de si nas coisas (Cf. MERLEAU-PONTY, 2006a, p. 439). Nesse sentido, "ver implica a possibilidade de se ver", uma lacuna, um "fantasma", uma "imagem", um "vazio por dentro", tal que ele é certo distanciamento em relação à imediação tátil. Como no mimetismo, cada elemento da Umwelt, cada visível "vê" o seu entorno e se molda segundo a visão que os outros tem dele. Desse Ineinander de fato emerge o Ineinander vivido, humano, como uma confirmação da Natureza. A Natureza exterior só pode ser conhecida pela interior, posto que esta confirma aquela, mas de tal modo que é a Natureza que possibilita a visão, já que ela é o fundo, o princípio anterior do Ineinandervivido. Corpo e coisas são feitos do mesmo material, do mesmo estofo, eles partilham de certas propriedades sensíveis. As coisas são réplicas do movimento corporal e este responde a questões que elas lhe fazem: entre corpo e coisas há uma tensão constitutiva, um movimento que se faz por esboços, os quais são resoluções particulares de questões que são modalizações de uma tensão geral.

Os esquemas corporais oferecem um resumo do mundo, a Umwelt é recortada pelas equivalências sensoriais (Cf. MERLEAU-PONTY, 2006a, p.349, 351), contudo a Natureza não é abarcada completamente por uma perspectiva corporal, nem mesmo pela pesquisa científica: "o ser visto é aqui menos que o ser" (MERLEAU-PONTY, 2006a, p. 382). A Natureza, Physis, é envolvente em relação à consciência e ao conhecimento humano (Cf. MERLEAU-PONTY, 2006a, p. 422, 428). Nesse sentido, a ciência se mostra como parte de uma história e não como coincidência com o ser. A Natureza permanece como ausência em cada tomada particular, como o negativo em face do qual algo se mostra. Dessa forma, não há coincidência possível com o Ser primordial, senão que somente por meio de criações humanas é que ele pode se desvelar. A Natureza só pode ser a Natureza percebida pelo homem (Cf. MERLEAU-PONTY, 2006a, p. 336), posto que ambas

\footnotetext{
${ }^{12}$ A Terra como Offenheit, abertura, "é um tipo de ser que contém todas as possibilidades ulteriores e lhes serve de berço” (MERLEAU-PONTY, 2006a, p. 127).
} 
compartilham determinadas propriedades, e ao mesmo tempo o percebido não está encerrado no sujeito perceptivo. A coisa e o mundo se definem pelo percebido, isto é, eles possuem uma sensibilidade própria, como no mimetismo, e eles não estão atrás da percepção humana, senão que são o núcleo dela (Cf. MERLEAU-PONTY, 2006a, p. 436). Há um isomorfismo entre o percebido e as coisas porque o percebido é uma modalização da sensibilidade própria da Natureza, porque o percebido está assim eminentemente no Ser (Cf. MERLEAU-PONTY, $2006 a$, p. 436, 351). Há, portanto, um "excesso do Ser sobre a consciência do Ser" (MERLEAU-PONTY, 2006a, p. 61).

A reversibilidade tocante tocado já está de alguma forma preparada pela própria sensibilidade da Natureza. No entanto, qual seria a condição de possibilidade de tal reversibilidade? Merleau-Ponty afirma que a análise do corpo deve esclarecer as análises anteriores - sobre as concepções históricas da Natureza e sobre a animalidade - e ser ao mesmo tempo esclarecida por elas. Os cursos anteriores haviam revelado certa teleologia do embrião em seu desenvolvimento, embora o desenvolvimento final não fosse dado no animal. A Natureza estaria no âmago do desenvolvimento do animal. Ao lado de Whitehead, Merleau-Ponty constata que a Natureza é passagem. Qual seria, entretanto, a condição de possibilidade, o estatuto mesmo de tal passagem? ${ }^{13}$

Ao procurar situar o corpo humano na Natureza, Merleau-Ponty comenta que ele já havia tratado disso em relação à animalidade (Cf. MERLEAU-PONTY, 2006a, p. 345). O fio articulador entre homem e animal é primeiramente essa passagem da Natureza, através da qual o embrião se desenvolve e um simbolismo aparece - embora este ainda seja primitivo no animal. Segundo, porque a atividade pelo prazer no animal torna-se corpo libidinal no homem: "o desejo humano emerge do desejo animal" (MERLEAU-PONTY, 2006a, p. 361). Isso significa que, pelo próprio desenvolvimento interno da Natureza, há "elevação" de estruturas, de modo que o superior é elevado a uma potência superior: entre o enxofre e o cão há diferença de organização, mas trata-se de um "mesmo produtor elevado a duas potências diferentes de organização" (Cf. MERLEAU-PONTY, 2006a, p. 66). Nas palavras de Merleau-Ponty, a estrutura estesiológica humana é uma estrutura libidinal (Cf. MERLEAU-PONTY, 2006a, p. 340). Ora, como a reversibilidade tocante tocado articula-se com a estrutura libidinal do corpo? Como a reflexão corporal (capacidade de se ver tocando) articula-se com essa estesiolo-

\footnotetext{
${ }^{13}$ Merleau-Ponty apresenta tal passagem ora como sucessão ora como não serial (Cf. MERLEAU-PONTY, 2006a, p. 357, 382, 399). Trata-se de dizer que a sucessão não acontece de maneira serial, como passagem entre instantes, de um flash a outro, ou como perfilamento de identidades. A passagem ou sucessão diz respeito à diferenciação, à reestruturação das configurações.
} 
gia libidinal, permitindo a Merleau-Ponty afirmar que a percepção é um modo do desejo (Cf. MERLEAU-PONTY, 2006a, p. 340)?

Segundo Merleau-Ponty, o nascimento de um corpo no mundo é o preenchimento de um vazio (Cf. MERLEAU-PONTY, 2006a, p. 338). Esse vazio, porém, nunca é preenchido completamente, senão que seu preenchimento é sempre postergado, ele é um "vazio sempre futuro" (MERLEAU-PONTY, 2006a, p. 340). Ao nascer, o corpo não traz um interior já pronto. Este só se desenvolve na relação com outrem, na relação especular em que minha referência a outrem e de outrem a mim possibilita a apreensão de si. A indivisão ou imbricação entre corpo, mundo e outrem (Cf. MERLEAU-PONTY, 2006a, p. 441) é uma relação especular, na qual um sujeito, ao ver-se no espelho e ao ser visto por outrem, introjeta uma imagem de si e ao mesmo tempo percebe os outros corpos com a mesma capacidade, isto é, como percipientes. A indivisão eu-mundo-outrem é assim uma promiscuidade (Cf. MERLEAU-PONTY, 2006a, p. 440), invasão ou projeção de mim no outro e do outro em mim (Cf. MERLEAU-PONTY, 2006a, p. 426). Dessa forma, o esquema corporal é, como salienta Ramos, "a perpétua busca de sua imagem no outro" (RAMOS, 2009, p. 231). Em outras palavras, a estrutura libidinal do corpo, ou o desejo, é a "busca do interior no exterior e do exterior no interior" (MERLEAU-PONTY, 2006a, p. 443). O corpo projeta-se nos outros e os introjeta porque ele os deseja. "O desejo considerado do ponto de vista transcendental", tal como assegura Merleau-Ponty, é "a membrura comum do meu corpo enquanto carnal e do mundo de outrem" (MERLEAU-PONTY, 2006a, p. 361). O nascimento de um corpo no mundo é a abertura de um campo, de uma polaridade, a iniciação em uma dimensão ou no circuito corpo-mundo (Cf. MERLEAUPONTY, 2006a, p. 445-446) porque a estrutura estesiológica é desejante. Com o ver inaugura-se um interior e um exterior (Cf. MERLEAU-PONTY, 2006a, p. 439) porque o esquema corporal, enquanto relação de ser entre corpo e mundo, é lacunar, vazio por dentro, isto é, desejo. Esse vazio possibilita a inserção de imagens, de corpos imaginários, assim como possibilita a "passagem para o exterior"; ele possibilita a incorporação (Cf. MERLEAU-PONTY, 2006a, p. 440), a imbricação dos corpos uns nos outros, a indivisão eu, mundo e outrem.

Segundo Saint Aubert, Merleau-Ponty trata o "desejo como incorporação e compreensão carnal do outro". Ele entende a sexualidade como estrutura ontológica, dimensionalidade primordial, "essa intencionalidade interior ao ser onde dois esquemas corporais se tomam um e outro por um só, onde uma carne tornase tudo isso que ela é ao co-nascer (com) uma outra carne" (SAINT AUBERT, 2013, p. 355, 356). 
A sensorialidade assim inaugurada, essa promiscuidade, é um investimento, afirma Merleau-Ponty, o que também pode ser nomeado como instituição. $O$ investimento é "vocação para um absoluto", "desejo de gratificação ilimitada" (MERLEAU-PONTY, 2006a, p. 442), posto que o sujeito sensorial ou corporal é desejo (Cf. MERLEAU-PONTY, 2006a, p. 443). Todavia, se o todo é o infinito (Cf. MERLEAU-PONTY, 2006a, p. 380), então o absoluto (todo) nunca pode ser atingido $^{14}$. Em consequência, o desejo dá ocasião ao prazer, possível fim da tensão desejo-mundo. O desejo, porém, não se sacia em prazeres particulares, indo sempre além, passando adiante. Como enunciado na Fenomenologia da percepção e em $A$ instituição - a passividade, ele é desejo do impossível, de uma eterna falta, de uma totalidade sempre ausente.

O desejo, ou o Eros, inicia uma dialética entre positivo e negativo, atual e possível, parte e todo (Cf. MERLEAU-PONTY, 2006a, p. 376, 446). Ele abre uma profundidade $^{15}$, um não-ser, uma negatividade natural (Cf. MERLEAU-PONTY, 2006a, p. 359). Uma tomada, uma manifestação, um prazer particular se realiza sempre em um horizonte de ausência, um infinito que nunca se doa, um negativo como o outro lado do positivo, o invisível do visível. Em um sistema diacrítico, a estrutura ou relação de ser corpo e mundo oferece-se como um sistema em que os signos se fazem pela diferenciação uns dos outros e não por identidades prévias; da mesma forma, o sensível é "ser por diferença e não por identidade" (MERLEAU-PONTY, 2006a, p. 382). Meu corpo se conhece por referência a outrem e vice-versa, o mesmo acontece na articulação tocante tocado, visível e invisível e na relação corpo e mundo: são as oposições que definem cada elemento do conjunto. Há, pois, um sistema de equivalências entre o dentro e o fora que faz com que um se realize por meio do outro. Nesse sentido, conclui Merleau-Ponty: "O corpo que tem sentido é também um corpo que deseja, e a estesiologia prolonga-se em uma teoria do corpo libidinal" (MERLEAU-PONTY, 1994, p. 380).

A reversibilidade tocante tocado é possibilitada pela estrutura libidinal do corpo, cada tomada (prazer) é um relaxamento particular que não fecha a abertura desejante total. Nesse sentido, as coisas são o que "falta ao corpo para fechar o

\footnotetext{
${ }^{14} \mathrm{O}$ todo não é um objeto ou uma substância: “O todo não é nada mais que a comunicação transversal entre os eventos”. A regeneração celular acontece, por exemplo, em referência a uma forma que não está ainda presente, isto é, ela acontece segundo a transversalidade ou o sentido diacrítico dos eventos. O todo é "a dimensão transversal que conecta todos os eventos espaço-temporais, como o eixo ao longo do qual os eventos são equivalentes, como uma melodia que não é nada mais do que as notas, mas precisamente na medida em que elas comunicam umas com as outras" (Barbaras, R. "A phenomenology of life”, p. 229).

${ }^{15}$ Segundo Saint Aubert, "a visão em profundidade torna-se um modelo privilegiado da relação da carne ao ser desejado, enquanto que a profundidade torna-se uma figura privilegiada do ser mesmo”. "A profundidade é tanto figura do ser como ele carrega esses nascimentos e sustenta esses surgimentos que são, no horizonte, as estruturas existenciais do desejo" (SAINT AUBERT, 2013, p. 393, 394; grifo meu).
} 
seu circuito", e o corpo sempre pede "outra coisa que não é corpo" (MERLEAUPONTY, 2006a, p.352). A atividade perceptiva, sendo feita para o que está ausente, é prospectiva, um movimento (Cf. MERLEAU-PONTY, 2006a, p. 356); ela é impulsionada pelo desejo, o qual define sua pregnância, sua fecundidade. A percepção se faz segundo um afastamento. Não, porém, o afastamento do corpo no futuro, remetendo a investida do mundo ao passado mais imediato, tal como acontecia na Fenomenologia da percepção, senão que um afastamento do todo infinito do mundo em relação a cada investida (tomada/prazer) do corpo. Essa negatividade torna possível um saber da Umwelt e um saber do corpo, isto é, um afastamento em relação ao ali da Umwelt. A perpétua remissão a um negativo, a algo outro além do que se manifesta, torna necessário que se defina o simbolismo no sentido de que cada termo é "expressão de um outro" (MERLEAU-PONTY, 2006a, p. 353). Há um sistema de equivalências em que cada elemento do conjunto é representativo (expressivo) de outro.

Em virtude do que foi visto, é preciso aproximar-se da tese de Ramos, a qual concebe o desejo como um modo ou dimensão do ser, de forma que ele aparece na intercorporeidade (RAMOS, 2009, p. 239), e chegar à tese de Saint Aubert, segundo o qual "a carne do mundo é essa concreção ontológica do desejo" (SAINT AUBERT, 2013, p. 386), entendendo assim o desejo como critério ontológico da carnalidade. O desejo é, enfim, intencionalidade, transcendência (Cf. SAINT AUBERT, 2013, p. 387), ele faz sair de si e participar no ser.

\section{CONCLUSÃO}

A necessidade de Merleau-Ponty superar os impasses de sua primeira fase o leva a estender a temporalidade à natureza ela mesma. Dessa forma, o corpo deixa de ser o portador do sentido - o que ainda acontecia na Fenomenologia da percepção - , já que no período maduro as coisas são significativas por si mesmas. Por outro lado, o critério de inteligibilidade das descrições e estruturas expostas deixa de ser apresentado como sendo tão somente a temporalidade. $O$ critério se aprofunda e passa a caracterizar a estrutura de funcionamento da própria temporalidade, isto é, da natureza e de todos os seus modos de aparecimento, como, por exemplo, o corpo humano. Esse novo critério é o desejo. Ele já havia aparecido nas obras iniciais do autor, em momentos dispersos e menos decisivos, como, por exemplo, no capítulo "O corpo como ser sexuado", da $\mathrm{Fe}$ nomenologia da percepção. Já nos textos maduros acontece a convergência entre 
desejo e temporalidade, de modo que o desejo se torna o âmago essencial da temporalidade, ou seja, o modo de ser fundamental da natureza.

\section{REFERENCIAS}

BARBARAS, R. Le tournant de l'expérience. Paris, Vrin, 1998.

BARBARAS, R. Le désir et la distance - Introduction à une phénoménologie de la perception. Paris: Vrin, 1999.

MERLEAU-PONTY, M. La Nature. Paris: Seuil, 1994.

MERLEAU-PONTY, M. A Natureza. Trad.: Álvaro Cabral. São Paulo: Martins Fontes, 2006a.

MERLEAU-PONTY, M. L'institution - la passivité. Paris: Belin, 2003.

MERLEAU-PONTY, M. Phénoménologie de la perception. Paris: Gallimard, 1995.

MERLEAU-PONTY, M. Fenomenologia da percepção. Trad.: Carlos Alberto Ribeiro de Moura. São Paulo: Martins Fontes, 2006b.

MOURA, C. A. R. Racionalidade e crise. São Paulo, Discurso Editorial e Editora UFPR, 2001.

RAMOS, S. S. A prosa de Dora: uma leitura da articulação entre natureza e cultura na filosofia de Merleau-Ponty. São Paulo : Edusp, 2013. (versão digital)

SAINT AUBERT, E. Etre et chair I - Du corps au désir: L'habilitation ontologique de la chair. Paris: Vrin, 2013. 